\title{
METHODOLOGICAL TRIANGULATION IN MOVEMENT PATTERN RESEARCH
}

\author{
Jacek Kotus, Michą Rzeszewski \\ Institute of Socio-Economic Geography and Spatial Management, Adam Mickiewicz University, Poznań, \\ Poland
}

Manuscript received: March 13, 2015

Revised version: October 10, 2015

Kotus J., Rzeszewsкi M., 2015. Methodological triangulation in movement pattern research. Quaestiones Geographicae 34(4), Bogucki Wydawnictwo Naukowe, Poznań, pp. 25-37, 1 fig. DOI 10.1515/quageo-2015-0034, ISSN 0137-477X.

ABSTRACT: The application of GIS and GPS methods together with qualitative sociological methods is one of the current fields of discussion in studies of human behaviour in space. The authors ask about the justification, manner and value of using the 'triad': quantitative GIS measurement methods - qualitative sociological methods - quasi-experiment. A mixed-method approach in an analysis of human movement patterns is introduced. Also, the role of the investigator in such projects is discussed.

KEY WORDS: methodological triangulation, movement pattern research, qualitative sociological methods, behavioural experiment, role of researcher

Jacek Kotus, Michał Rzeszewski, Institute of Socio-Economic Geography and Spatial Management, Adam Mickiewicz University, ul. Dzięgielowa 27,61-680 Poznań,Poland; e-mail: tatra@amu.edu.pl,mrz@amu.edu.pl

\section{Introduction}

Studies of the dynamics of human spatial behaviour and paths of social behaviour in everyday and extreme situations are among well-grounded directions of scientific activity in geography discussed for many decades now. An analysis of spatial behaviour is one of key cognitive activities in tourist research (McKercher, Lau 2008; Lee, Joh 2010; Shoval, Isaacson 2007, 2010), identification of social and unsocial types of behaviour of city dwellers (Chainey, Ratcliffe 2008), analysis of consumer behaviour patterns (Dogu, Erkip 2000; Chebat et al. 2005), and spatial perception and cognition (Dolins, Mitchell 2010). The research at both a micro- and a macro-scale (McKenzie, Debbage 1990; González et al. 2008; Song et al. 2010) shows how everyday space users make their choices and solve spatial questions, which allows formulating answers to purely cognitive questions as well as working out practical recommendations. This wide area of inquiry still enjoys new prospects of development (Golledge, Stimson 1997; Sheller, Urry 2006; Amedeo et al. 2009).

Important in the development of this research area is also the discussion of the various research methods in human geography that concentrate on a multi- or an interdisciplinary approach, which allows a better, more precise way of examining phenomena (Philip 1998; Driver 2001; Mendoza, Crang 2002; More'n-Alegret 2012). This involves the elimination of a mere 'subjective certainty' in the researcher's standpoint and getting closer to 'objective truth'. ${ }^{1}$

1 Being aware of the complexity of the terms 'subjective certainty' and 'objective truth', we put them in inverted commas. 
Over the last decades new technologies have started to figure more and more prominently in social geographical research (Kidner et al. 2003), one of the tools that play a leading role in spatial behaviour analysis being the Global Positioning System (GPS). This technique of registering human movement offers highly precise, multi-aspect measurements (DeLyser, Sui 2012), but it can also produce a misleading belief that by registering a type of behaviour we arrive at an explanation of the phenomenon studied. In this case it is only a combination of the new technologies with social research techniques that makes it possible to explain spatial behaviour patterns as well as the motives for and effects of adopting them. Combined with social knowledge, the geographic information systems (GIS) and GPS technologies offer highly novel and interesting forms of research (Moles 2008; Evans, Jones 2011). However, it seems that in many cases human geography plays a leading role only superficially (Shoval et al. 2014). By concentrating only on their identification through registration, one can merely find some regularities. It is impossible to explain their causes in this way. Should geography only register spatial behaviour, or explain it together with its motives and possible consequences? If we choose the latter and expand our perspective (using many research tools), we shall also expand out explanation horizons. In any other case we in fact confine ourselves to 'subjective certainty'.

Thus, research progress has two aspects: greater profundity in explaining phenomena with a greater ability to recommend the results for practice, and expanding the range of the reality studied by using the triangulation of methods. However, the use of sociological and psychological techniques gives rise to the practical question of the way/ procedure of carrying out a mixed type of research in studies of movement patterns. Also, moving in a borderland between various disciplines is a creative venture, but it can also involve threats, if only such as unskilful use of those research techniques. Therefore, reflection is needed on the role that the researcher does, and can, assume in this kind of methodological triangulation. The aim of this paper is to propose a procedure for using a mixed-method approach in the research on movement patterns and to reflect on the role of the researcher in such projects.

\section{Methodological triangulation in human geography}

Social life is multi-dimensional. On the one hand, this statement expresses a truism, but on the other, a deep and usually not fully discovered truth. This multi-dimensionality is reinforced by social reflections made in human geography (Hägerstrand 1970). The spatial plane meets the time plane here, but analyses conducted in the space-time dimension are not the only planes of explanation of social behaviour in space (Thrift 2005). A third plane integral with them is the psycho-social dimension of each case of social behaviour taking place in space and time that embraces motives underlying both individual and group activities (Rocheleau 1995). Thus, it appears that social life occurring in space and time poses a complex research challenge. The discovery of phenomena of this type in their true senses and meanings can be compared to a description of a mountain. Each individual description will be simplifying and far from full. It is only a variety of viewpoints, from closer and farther perspectives as well as different directions, that will allow collecting enough data to create a virtual model of the mountain in 3D format.

The situation is similar in the study of human spatial behaviour patterns. To identify them, it is simply necessary to conduct research, and then explanatory narration, from a variety of perspectives. Naturally, there appears the question of whether the human geographer should venture into research fields of other disciplines, or whether he should rather focus on applying a precise research procedure at the space-time plane. Both the literature on the subject and the research assumption we have presented earlier suggest an answer that, yes, he should, or even must, use all the research methods he knows in order to arrive at the truth (Rocheleau 1995; Philip 1998; Crang 2002), taking care all the time not to surpass certain limits, e.g. ethical, in applying some methods. 
The dilemma of a full description of a phenomenon (limited only by the existing body of knowledge about the subject matter at hand) has been solved by representatives of the social sciences. Sociologists, who constantly face allegations of an incomplete description of social life, have formulated the rule of the triangulation of social research (Denzin 1978; Denzin, Lincoln 1994; Hussein 2009). By assumption, it is supposed to eliminate possible niches and gaps in research, and in effect allow a full description and explanation of the phenomenon studied. This approach involves the triangulation: of a theory, of researchers, of data, and of methods. The triangulation of methods that interests us in this paper assumes the use of more than two research methods, as different as possible and offering tools to examine phenomena in a variety of relations (Jick 1979). This seems to be a key assumption in studies of movement patterns by GIS tracking if research of this type is to develop and lead to an explanation of human spatial behaviour (Ricketts et al. 2008; Gibson et al. 2010).

The research procedures employed can follow two sequences of techniques (Fig. 1). A study can start with a focus group interview (FGI) as a pre-research method:

- A - an FGI to obtain initial opinions of research participants;

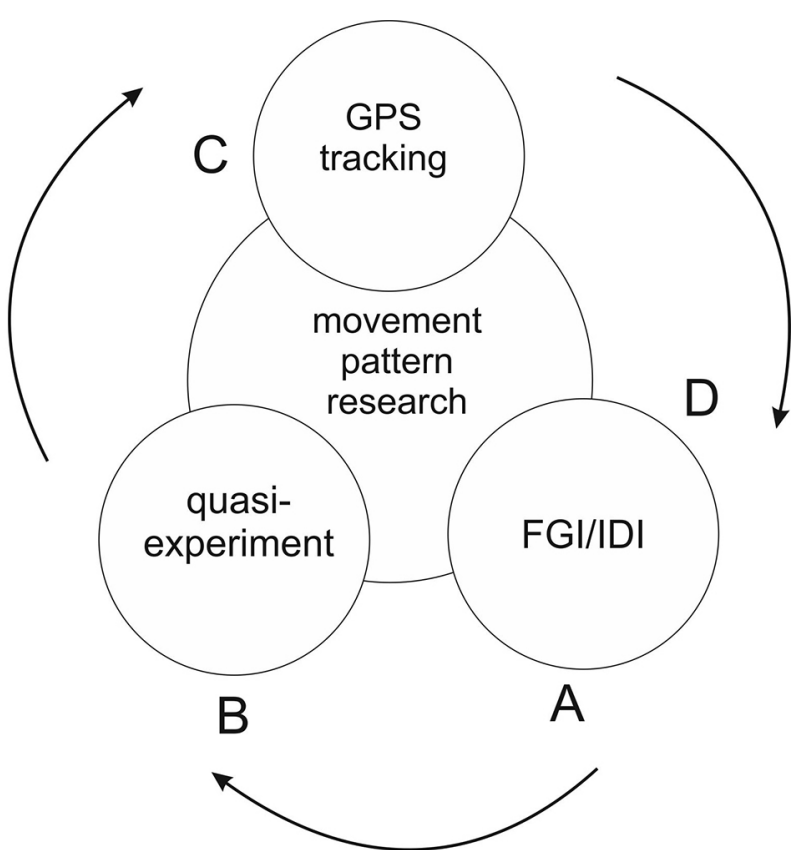

Fig. 1. Methodological triangulation in movement pattern research

Source: authors' idea
- B - a behavioural quasi-experiment to introduce controlled variables and arrange selected stimuli in the course of the research;

- C - GPS tracking; and

- D - an in-depth interview (IDI) to justify the motives underlying individual activities and traces registered.

Or the research can follow a path starting with an IDI as a pre-research method:

- A - an IDI to identify individual profiles of the participants (motives, opinions, attitudes);

- B - a behavioural quasi-experiment to introduce controlled variables and arrange selected stimuli in the course of the research;

- C - GPS tracking; and

- D - an FGI to identify collective attitudes and opinions reinforced by the conformity of the group and an escalation of behaviour (opinions) characteristic of group dynamics.

\section{Movement pattern research using GPS tracking}

There have been few technologies that have affected the methodology of research on spatial phenomena in an equally significant and permanent way as the Global Positioning System (GPS). GPS tracking is used in many disciplines: from medicine (Miskelly 2005; Richardson et al. 2013), through tourist behaviour (Xia 2008, 2011; Shoval, Isaacson 2007), tourist traffic in protected areas (Orellana et al. 2012; Shoval 2008; Shoval, Isaacson 2010), location-based services (Li 2006; Millonig, Gartner 2007), to environmental health (Rainham et al. 2008; Zenk et al. 2011). The possibility of a relatively easy, fast and precise measurement of a position has paved the way to several new research techniques also in human geography. It is no wonder that this method aroused the greatest interest in space-time geography, especially in transport studies where it was first applied. In the initial period, GPS facilities were used to trace and analyse pathways of motor vehicles in studies of road traffic (Zito et al. 1995; Quiroga, Bullock 1998). The next stage was an analysis of daily movement within a household, also with the help of equipment mounted in cars, as in the pioneering so-called Lexington study (Murakami, Wagner 1999). Both here and in similar studies from this period (Doherty et al. 1999; Stopher, Wilmot 2000), the GPS technology served as complemen- 
tary to more traditional techniques of behaviour registration, like travel diaries, and its role was often limited to a verification of conclusions obtained with the help of other methods. The use of facilities mounted in cars was largely due to their many technical limitations of that time and a poorly developed methodology of such research. GPS receivers were comparatively big, which made them hard to carry on a person, they required considerable amounts of energy, which limited the time of continuous measurement, the interface required the user to have a specialised training, and the precision of the location determined was relatively low, on the order of some tens of metres (before the SA signal was turned off in 2000). Car mounting bypassed several of those problems: the GPS started registering the moment the car began moving without an active part of the person involved, and energy was not a limitation. Additionally, deficiencies of precision were largely made up for by comparing the route recorded with the existing road network.

The idea of employing the GPS technology in the research on human behaviour in space at a scale of a single individual probably also appeared in that period, which was due to the imperfections of methods of pedestrian mobility registration used so far. The most popular of them was a space-time budget or diary, allowing a record of activities of participants over a short time interval (Anderson 1971; Thornton et al. 1997). While it has often brought very good results (Janelle et al. 1988), it has several limitations. First of all, it requires an active, conscious and burdensome involvement of the participating persons themselves. In recording information in their diaries, the participants often commit mistakes, whether because they want to conceal some activities, or do not remember precisely the sequence of events, or have not made an exact measurement of time, and this produces results departing from the researcher's expectations (Szalai 1972). Like other similar techniques, e.g. interviews with participants, this method is imperfect because of the very course of cognitive processes and the impossibility of their faithful description with the help of linguistic structures (Nisbett, Wilson 1977). In this context, the GPS technique makes it possible to introduce an objective element in the form of real paths of human movement obtained practically in real time, with a very high resolution of a few seconds and an adequate precision. A pioneer of its use to trace individual persons was Reginald D. Golledge in his study of pedestrian routes for the visually impaired (Golledge et al. 1998). When the error-generating SA signal was turned off in 2000, civilian receivers attained the level of accuracy required to determine the actual position of a pedestrian, but even so GPS-based studies of human movement were still very rare, one of the exceptions being a research on exposure to environmental pollution (Philips et al. 2001; Elgethun et al. 2003). The precision obtained suggested that GPS tracking could not only complement travel diaries kept so far, but even replace them as a basic source of data (Wolf et al. 2001, 2003). However, it was only the development of computer and communication technologies as well as the GIS, and especially an increase in the availability and advancement of GPS locators, that made possible their wider use in the research on human behaviour in space. Today GPS receivers can be found in practically all new mobile facilities: smartphones, netbooks, tablets, and even sport-oriented gadgets like pedometers and photometers. Also available are specialised GPS locators, both passive and active, that allow 24-hour registration with no undue trouble for the user. All this has created many new possibilities of obtaining high-quality spatial and temporal data (Shoval 2008; Shoval, Isaacson 2006).

Still, the use of the GPS technology to trace human movement patterns is not without problems. They concern both, technological limitations and the research process itself. The nature of locating via satellite signals makes the force of a signal and measurement precision changeable over space and time, which is felt especially acutely in an urban milieu, i.e. one that is most interesting to us in terms of human geography. As a result, there appear measurement errors and gaps in the record that are sometimes hard to interpret, because a similar trace is left by the lack of a signal caused by poor visibility of the sky, an equipment failure, or a visit of a participant in a building that can be a significant point in interpretation. Another problem is the awareness of the participants of the very fact of being monitored, which can affect the activities they undertake. Shoval and Isaacson (2006) note that the only way for the tracking device not to disturb 
or affect the activity of the pedestrian observed is for it to be both small and passive. It seems, however, that in spite of the miniaturisation of facilities, the reduction of problems with their loading and a maximum simplification of the interface, the studied persons are still aware of participating in a situation unnatural for themselves and can behave in a way departing from usual. Especially that in a considerable number of states the research ethics and legal regulations require the participants to be informed about the nature of the study and the kind of information collected (Kwan 2012).

The research based on GPS tracking also faces the problem of the interpretation of the data obtained, because raw location data do not yield information about motives of human movements. In other words, we can learn, for example, which parts of the city tourists visit most frequently and in what order, but not what objects and places have attracted their attention. This is significant because in this way all kinds of mistakes can appear in the results of analyses, especially if we have not got a very accurate knowledge of the given place: the most often visited areas can be saturated with historical monuments and tourist attractions, but they can equally well be merely a place of residence, an eating facility, a public transport node, or have no objects of interest but offer, say, a good view of the city centre. This problem is the more serious the smaller the scale at which we want to know the spatial behaviour of the group examined.

It seems that today the development of GPS tracking methods goes in the direction of increasingly advanced data processing and analysis, e.g. through the use of semi-Markov processes (Xia et al. 2011), or perfecting methods of identification of movement stops (Orellana et al. 2012; Orellana, Wachowicz 2011). Still, there is a gap in the knowledge of the motivation, experiences and actual, not only interpreted, destinations of the persons studied. Recently, attempts have been made to remedy this situation using all kinds of questionnaires, interviews and sketch maps (Petterson, Zillineger 2011; Greenberg Raanan, Shoval 2014), and while this is a promising direction, one might note that, in the context of analyses of social phenomena, those are not advanced but very basic methods. In the social sciences, as in human geography itself, one can find methods that are much more penetrating and objectively analyse motives of behaviour; one of the examples is the focus group interview proposed in this article. The potential lying in the triangulation of GPS tracking methods with qualitative ones seems very great, but its full use is only possible on the assumption that advanced techniques of measuring movement patterns will be accompanied by equally advanced techniques supporting the interpretation of human spatial behaviour.

\section{Movement pattern research using sociological qualitative methods: FGI/ IDI}

The focus group interview (FGI) and the individual in-depth interview (IDI), as sedentary social techniques, are perhaps the most popular sociological qualitative methods today, also in human geography (Brannen 1992; Kitzinger 1995; Bailey et al. 1999; Elwood, Martin 2000; Bennett 2002; Longhurst 2003). Here this type of qualitative research can be found in gender and ethnic studies (Wilkinson 1998; Pratt 2002), segregation (Greenberg Raanan, Shoval 2014), or sense-of-place research (Mendoza, More'n-Alegret 2012). Qualitative research methods are increasingly popular with specialists in the field of GIS and PPGIS (Talen 2000; Dennis 2006; Kwan, Knigge 2006; Pavlovskaya 2006; Cope, Elwood 2009; Lowery, Morse 2013). In this case, use is often made of relatively new methods instead of, or as a supplement to, classical qualitative ones, e.g. different types of a walking interview (Wylie 2005; Ingold, Lee 2008; Carpiano 2009; Evans, Jones 2011). Among its strong points as a type of qualitative study is the fact that "walking with interviewees generates more place-specific data than sedentary interviews. Walking interviews tend to be longer and more spatially focused, engaging to a greater extent with features in the area under study than with the autobiographical narrative of interviewees" (Evans, Jones 2011: 856).

However, scholars employing this technique admit that it has limitations: "... high levels of background noise, which does not appear to be a significant barrier to interviewees spending time in a particular space" (Evans, Jones 2011: 857). In our opinion, the weaknesses, especially in an urban environment, also include an adverse effect of the presence of third persons in the street, 
crowds, or the unpredictability of the appearance of sudden new stimuli that can affect the interview. Another significant drawback, we think, is the impossibility of determining the influence of the researcher conducting a walking interview on the spatial behaviour of the interviewee and his or her perception of the surroundings.

Undoubtedly, qualitative social research enriches studies carried out in a space-time perspective with motives of actions taken (Goss, Leinbach 1996; Gibson et al. 2010). This is right also in the opinion of the present authors, which they voiced in earlier paragraphs. It seems, however, that there is a serious danger of:

- developing and applying qualitative methods that interfere with the registration of movement or that alter the spatial behaviour of those under study, as pointed out earlier, and

- an exchangeable use of focus interviews and IDIs as simply qualitative methods, without due attention paid to the differences between those methods.

Only rarely can one hear that each qualitative research method is different, and it is a methodological mistake to use them on a par and interchangeably. Each technique can be applied with a view to attaining various goals: identification of deeply rooted individual opinions, opinions of a collective resulting from interactions among its members at the time of study, identification of imaginings, etc. (Creswell 2003; Brookfield et al. 2013). Thus, the stipulation that qualitative methods should be employed to supplement geographers' inquiries is certainly right, but it can also lead to their uncritical use. Let us therefore emphasise once more: qualitative methods differ from one another and should be employed in full awareness of the goal that the researcher seeks to reach. Thus, the FGI technique, which goes back to the 1940s and '50s, is primarily a qualitative study registering opinions of a group and identifying collective (not to say 'conformist') judgements. Let us add: a group profiled according to a characteristic already when choosing people for study. One of the basic requirements for a focus group is its homogeneity in terms of one, at most two, social features. The group is to have a common denominator in a socio-demographic profile, e.g. age and place of residence, sex, and political opinions. By this move we can learn, fast and in an in-depth way, the opinions, attitudes and motives of behaviour of a community defined by a certain profile (Krueger, Casey 2008). What is intended during a discussion of a focus group is the activation of deep group judgements and attitudes rather than a conflicting interaction and the individuality of behaviour.

Unlike this type of research, the IDI is a technique employing individual interviews to seek personal opinions, motives, attitudes, and references to prevailing judgements. An IDI allows a more or less standardised talk with the interviewee in a face-to-face situation.

In the previous chapter, a 4-stage application of a mixed type of research was proposed. A differentiation was made between FGI and IDI at two points of the procedure. This, we think, is important for the attainment of our ultimate goal: the research on individual movement patterns, or the research on group movement patterns.

In the case of the research on individual movement patterns using GIS tracking, an FGI applied before the study is useful in gaining an initial knowledge of the existing opinions, customs, thought schemata, and attitudes of persons qualified for individual behaviour registration in a behavioural quasi-experiment. Apart from the initial knowledge about research participants, we obtain data that can be useful in modifying independent elements of the quasi-experiment should it be repeated in the future. As a pre-research method, the FGI is also a way of making the participants familiar with the researcher and the situation when their behaviour is being registered. In turn, an IDI applied as a post-research method deepens the knowledge about the behaviour registered. With behaviour paths identified and their course known, one can learn more about what prompted this and not that individual spatial decision. In this case group conformity activated during the FGI would act against the researcher striving to get at individual motives.

The application of those two methods in reverse order: a pre-research IDI and a post-research FGI, facilitates a study of group movement patterns. Its aim is to identify spatial behaviour patterns and their underlying motivation in a group activity (one 8-person group or several smaller, e.g. $3-, 4-$, or 5-person units). In the course of a group interview used as a post-research method, the participants will be more willing to reveal group 
motives that decided them to behave in one way rather than another. Collective motivations and attitudes would disappear in an IDI study.

\section{Movement pattern research using a behavioural quasi-experiment}

Widely known in the scholarly circles is the cooperation between behavioural geographers and psychologists (Garling, Golledge 1993). Experimental and derivative methods can be used primarily in studies of human behaviour in spatial settings, cognition of space, and how people acquire spatial knowledge (Amedeo et al. 2009). However, it should be noted that what qualifies a research as experimental is not the technique itself (e.g. creating sketch maps or mental maps), but rather the conditions in which it is conducted. Actual use of psychological methods of an experiment (with its methodological requirements) and a quasi-experiment in movement pattern research is fairly rare, if not altogether absent. Scholars focusing on spatial issues tend to employ simulations definitely more often (Conte et al. 1997; Batty 2005; Santé et al. 2010) than forms of an experiment or quasi-experiment (Aspinall et al. 2013), although there are works in the field of human geography that combine a simulation and an experiment (Eck, Liu 2008; Janarthanam et al. 2012, 2013; Aspinall et al. 2013; Mackaness et al. 2014). While unaware of the reasons underlying such choices, one can suppose that many researchers find the non-interactive method of simulation simpler to use. An experiment and a quasi-experiment assume interactive contact with their participants. This, in turn, requires the researcher to develop social knowledge and skills, i.e. an additional (specific) research competence. Apart from all, experimental methods involve the control of many variables, hardly controllable in the "urban laboratory" (Kirk 1995; Prince et al. 2012; Dziak et al. 2012). In the latest literature on movement pattern research using GPS tracking, one can find single works relying on the mechanism of methodological triangulation and quasi-experiments, although the researchers themselves do not use those notions in the description of their research methods (Greenberg Raanan, Shoval 2014).

An important question that can be asked when studying spatial behaviour is: why is a quasi-ex- periment proposed and preferred, rather that its full psychological version? This is due to the specificity of the research on movement patterns and a supportive, though parallel, role of a quasi-experiment. In a quasi-experiment there is usually no control group and no pre-test. Also, there is a less restrictive approach to the invariability of dependent conditions that are not under the researcher's control. When writing about an experiment, scholars associated with Golledge state explicitly that "conducting experiments in the real world can be a hazardous business" (Amedeo et al. 2009: 117). What is left is a quasi-experiment, then. In this type of research on human spatial behaviour, there is a group of variables that remain (but that also can remain) beyond the researcher's control (Thyer 2012).

Is it necessary and justified to propose quasi-experimental methods in the movement pattern research using GIS tracking? Naturally, a study of this type is often conducted at a large scale and employs quantitative methods, like a real-time analysis of data from cellular telephony (Ratti et al. 2006), or from carriers leaving a trace in the form of electronic information (González et al. 2008; Liu et al. 2010). The data thus collected form mobile patterns, inform about trends, and can serve to anticipate specific types of behaviour or the carrying capacity of a given area. Using quasi-experimental methods at such a large scale of research could mean losing control over the quasi-experiment, and in effect exposing both the participants and third persons to some danger. Implementing a behavioural quasi-experiment is possible and useful when studying phenomena at a smaller scale. The aim of the research is an indepth analysis of individual or group behaviour in defined situations, and not establishing behaviour schemata of the population. A behavioural quasi-experiment consists in this case in giving participants facilities registering their movements in space and time and formulating tasks: bringing a tourist to an unknown city in order to examine the mechanism of learning it as well as the concentration and deconcentration of behaviour, identifying spatial behaviour on a student campus in order to identify spaces that are more or less social, testing the efficiency of escape routes, tracing the activities of visitors on trails in a national park, etc. Then it is possible to control such social variables as: 
- the number of persons or groups in each study conducted,

- the structure of the groups examined, and

- socio-demographic profiles of individuals.

Of course, independent variables can also be time and the kind of space. The use of methods of a behavioural quasi-experiment in the research on movement patterns by GIS tracking allows the repeatability of registration after changing the stimuli. Finally, when carrying out a behavioural quasi-experiment, we have control over the participants and access to them. A quasi-experiment makes it easier to conduct an in-depth qualitative study both before and after each stage of quasi-experimental registration. Naturally, as in each experiment, also this type of method can pose some threats, reinforced by its somewhat milder rules. This demands great scrupulousness in its design on the part of the researcher.

\section{Role of the modern researcher in a study of human movement patterns}

While a scientific discipline can be advanced by a change in the way a research is conducted involving an expansion of methods employed and perspectives of viewing the reality as well as the deepening of the explanation of the reality examined, such a change also creates some dangers. Dowling (2009: 595) lists three social roles of the researcher that kept changing with the development of human geography:

\section{“Stage 1}

In positivist human geography (as practised, for instance, in most of contemporary GIS), researchers document the social world rather than being immersed in it, or play a role in changing it.

\section{Stage 2}

Qualitative human geography, in particular, as practised in contemporary cultural geography, envisages research to be a part of, and constructive of, societal processes. Those researched are hence participants or respondents, and the research relationship requires recognition and negotiation of intersubjectivity rather than objectivity.

\section{Stage 3}

Finally, in critical human geography, research, by its very nature, does and should effect social change. Action research methodologies emanate from this framework, with subjects/ participants identified as co-researchers and co-creators of knowledge. The key ethical issue in this framework is the purpose and use of research, and its potential to challenge and transform dominant power structures and relations."

Those remarks, naturally, also refer to human spatial behaviour and the movement pattern research. By expanding the scope of the research we change the researcher's competence. This, in turn, has an influence, whether he is conscious of it or not, on his role in the research.

The use of qualitative methods introduces social interaction and face-to-face relations at the researcher-participant level. The researcher has to accommodate the participant's attitudes in the research procedure. Communicative qualitative methods serve to release those attitudes and define his agency and creative role. The ethics of qualitative social studies is an especially important element of this type of exploration. There is some discussion in the literature on the role of the researcher not only as one who conducts a study, but also as a social activist mobilising and educating research participants. In selected cases, participatory action research can be an interesting and welcome addition to/ extension of the basic role the researcher performs (Fisher, Ball 2003; Pain, Francis 2003; Cameron, Gibson 2005; Kindon et al. 2007; Pain, Kindon 2007). The use of interactive qualitative sociological methods can encourage the researcher to involve the participant in the research process even more. Ethics becomes one of the major issues in research (Mertens, Ginsberg 2008; Research ethics code of practice 2008; British Psychological Society 2009). On the one hand, there are two basic principles of the researcher's ethics:

- taking care not to influence the research results through interaction with the participants, and

- taking care not to trespass on the privacy of the person or persons studied.

On the other hand, adherents of participatory action research emphasise that endowing participants with agency is more responsible, partner-like and egalitarian on the part of the researcher (Pain 2008; Durham Community 2011). 
In our opinion, in qualitative sociological studies carried out together with the procedures of movement pattern research, too great an involvement of participants can lead to a falsification of results and to creating artefacts. A fundamental argument in this case is taking care for a social study to cause as little change in the participants' opinions and attitudes as possible, and hence also in their spatial behaviour that is then to be registered. It is very important to realise the weight of this matter, because it is easy to infringe upon rules unintentionally. As part of the pre-research procedure, the researcher should explain to the participants the purposes of his research and its successive stages. At each moment they should be fully aware of his actions.

At this point there appears a dilemma between informing the participants about individual stages of the study and the effect that an FGI as a pre-research method may have on the results of measurements registered in a quasi-experiment. The researcher may provoke some types of behaviour by his judgements, but also a participant may want to endear himself to the researcher and meet his research expectations. The requirement of informing participants certainly clashes with the naturalness of their behaviour, opinions and attitudes. Similarly, post-research qualitative methods can be disturbed by face-to-face relations, especially when the researcher is already in possession of the results of his movement pattern study. The awareness of those results is important in terms of explaining individual movement paths and finding motives that underlie individual and group types of behaviour. However, movement-related knowledge can lead the researcher to suggest to the participants some interpretations of their behaviour.

In our opinion, two basic kinds of movement pattern research employing qualitative methods can be distinguished depending on the degree of agency assigned to participants:

- a classical research of the top-down type in which it is the scholar who initiates the study and who draws outsiders into a researcher-participant relation, and

- a contemporary, bottom-up modification of empirical activities in which a group of activists, a local community, or a social movement invites a scholar to take part in an activity in the role of an expert, consultant, partner, or research designer.

In the first case, the scholar should remain in an asymmetric role of an objectivising researcher. In the other case, he becomes a partner and in fact a co-researcher.

The conclusion is as follows: as never before in human geography, the development of interdisciplinary studies within geographical sub-disciplines calls for creating and using an ethical code. The research on movement patterns by GIS tracking becomes increasingly invasive socially. The invasiveness appears at all three, the pre-research, research proper and post-research stages, and is due to the fact that researchers not only register behaviour, but also seek to explain it.

\section{Final conclusions}

Many years ago human geographers started a discussion about the use of knowledge from other disciplines in the research on human behaviour and movement patterns. The beginning of the 21 st century and the last decades have added a new thread to those reflections. Today a human geographer can resort to the latest technologies to register human behaviour. This can now be done not only in a very precise, but also massive way. New GIS- and GPS-related technologies enable studies that are interesting in cognitive terms and of practical significance. However, with such technological support, the human geographer, as never before, faces the threat of relying too much on a single method. Very important is a discerning and multi-aspect approach to research that allows not only the registration of behaviour, but also its explanation. Qualitative social research and the design of a quasi-experiment discussed in this paper as a complex procedure included in the movement pattern research by GIS tracking is an example of such an approach.

The use of methodological triangulation in the research on movement patterns involves the danger of a too intuitive and free application of qualitative and experimental methods. The more so if the geographer is a specialist in the application of GPS/GIS methods and treats qualitative research as a complementary (in other words, less important) type of study. As a result, he can employ the methodological triangulation we propose in 
an asymmetric way, with quantitative methods privileged (Big Data research) or with no proper control over the qualitative and experimental procedures. This warning is not intended to scare scholars away from triangulation, but rather to be a stimulus for those geographers who are interested in behavioural inquiry to develop their research skills.

In a study where methodological triangulation is applied, it is highly important for the researcher to control the method (or methods) employed rather than for the method to dictate the scholar's steps. This stipulation leads to three conclusions. First, the researcher should observe procedures in his actions, as mentioned in the previous paragraphs. The second conclusion refers to the researcher's ethical conduct, whether in choosing people for his study, pre-research and research proper, or at post-research stages and during the storage of source data (recordings of pictures, sounds, personal data, images of persons examined, and traces of their behaviour). The third conclusion, perhaps the most controversial one in the light of the modern literature on the subject, is that the researcher should terminate his inquiry when it stops bringing cognitive effects and starts creating social life. Naturally, all results made public, even in the form of final cognitive conclusions, can influence further social life. In this case, however, what we mean is the direct effect of the research rather than its collected, processed and published results. As mentioned earlier, this is to some extent in counterpoint to the participatory action research so animatedly discussed today. However, the use of methodological triangulation that includes methods of behaviour registration, individual and group interviews, as well as controlled quasi-experimental variables can lead to excessive and uncontrolled interference in the lives of the people studied. We think, therefore, that cooperation of participants with scholars on a participatory action basis should rather be avoided.

To sum up, the methodological triangulation of movement pattern research by GPS tracking conducted with due care to procedures demanded by each method reinforces especially the kind of geographical inquiry carried out at a micro-scale that concentrates on methodological individuality (in opposition to holism), and seeks to explain the phenomenon under study on the basis of an analysis from a variety of perspectives. It is in this type of research, we believe, that the full potential of research on movement patterns can be used. Unlike the Big Data type of analysis, a study at a micro-scale allows not only finding an answer to questions about the dynamics of movement (its intensity, direction and volume), but also (and perhaps first of all) identifying types of social behaviour combined with motives, causes and limits of (barriers to) its adoption.

\section{Acknowledgements}

We would like to thank the Polish National Science Centre, which supported this work by a grant project no. UMO-2011/03/B/HS4/01171.

\section{References}

Amedeo D., Golledge R.G., Stimson R.J., 2009. Person-environment-behavior research: Investigating activities and experiences in spaces and environments. Guilford Press, New York, London.

Anderson J., 1971. Space-time budgets and activity studies in urban geography and planning. Environment and Planning 3(4): 353-368.

Aspinall P., Mavros P., Coyne R., Roe J., 2013. The urban brain: Analysing outdoor physical activity with mobile EEG. British Journal of Sports Medicine, BJSM Online First, published on March 6, 2013 as 10.1136/bjsports-2012-091877 1-7. Available at: http:// bjsm.bmj.com/ content/ early/ 2013/03/05/ bjsports-2012-091877.full (accessed 13 March 2014).

Bailey C., White C., Pain R., 1999. Evaluating qualitative research, dealing with the tensions between 'science' and 'creativity'. Area 31(2): 169-183.

Batty M., 2005. Agents, cells, and cities: New representational models for simulating multiscale urban dynamics. Environment and Planning A 37(8): 1373-1394.

Bennett K., 2002. Interviews and focus groups. In: Shurmer-Smith P. (ed.), Doing cultural geography. Sage, London: 151-162.

Brannen J., 1992. Combining qualitative and quantitative approaches: An overview. Avebury, Aldershot.

British Psychological Society, 2009. Code of Ethics and Conduct Guidance. Ethics Committee of the British Psychological Society. Available at: www.bps.org.uk (accessed 11 March 2014).

Brookfield K., Bloodworth A., Mohan J., 2013. Engaging residents' groups in planning using focus groups. Proceedings of the ICE - Engineering Sustainability 166(2): 61-74.

Cameron J., Gibson K., 2005. Participatory action research in a poststructuralist vein. Geoforum 36(3): 315-331.

Carpiano R.M., 2009. Come take a walk with me: The "goalong" interview as a novel method for studying the implications of place for health and well-being. Health $\mathcal{E}$ Place 15: 263-272. 
Chainey S., Ratcliffe J., 2008. GIS and crime mapping. John Wiley and Sons, West Sussex.

Chebat J.Ch., Gélinas-Chebat C., Therrien K., 2005. Lost in a mall, the effects of gender, familiarity with the shopping mall and the shopping values on shoppers' wayfinding processes. Journal of Business Research 58(11): 1590-1598.

Conte R., Hegselmann R., Terna P., 1997. Simulating social phenomena. Springer, Berlin.

Cope M., Elwood S., 2009. Qualitative GIS. Sage, London.

Crang M., 2002. Qualitative methods: The new orthodoxy? Progress in Human Geography 26(5): 647-655.

Creswell J.W., 2003. Research design: Qualitative, quantitative, and mixed methods approaches. Sage, Thousand Oaks, London.

DeLyser D., Sui D., 2012. Crossing the qualitative-quantitative divide II: Inventive approaches to big data, mobile methods, and rhythm analysis. Progress in Human Geography 37(2): 293-305.

Dennis S.F., 2006. Prospects for qualitative GIS at the intersection of youth development and participatory urban planning. Environment and Planning A 38(11): 2039-2054.

Denzin N.K., 1978. The research act: A theoretical introduction to sociological methods. McGraw-Hill, New York.

Denzin N.K., Lincoln Y.S. (eds), 1994. Handbook of qualitative research. Sage, Thousand Oaks, London.

Dogu U., Erkip F., 2000. Spatial factors affecting wayfinding and orientation: A case study in a shopping mall. Environment and Behavior 32(6): 731-755.

Doherty S.T., Noël N., Gosselin M.L., Sirois C., Ueno M., 1999. Moving beyond observed outcomes: Integrating global positioning systems and interactive computer-based travel behavior surveys. Transportation Research E-Circular Washington, D.C. 449-467. Available at: www.trb.org (accessed 11 March 2014).

Dolins F.L., Mitchell R.W., 2010. Spatial cognition, spatial perception mapping the self and space. University Press, Cambridge.

Dowling R., 2009. Ethical issues in research. In: Kitchin R., Thrift N. (eds), International Encyclopedia of Human Geography. Elsevier, Oxford: 595-600.

Driver F., 2001. Human geography, social science, the arts and the humanities. Area 33(4): 431-434.

Durham Community Research Team Centre for Social Justice and Community Action, Durham University, 2011. Community-based participatory research: Ethical challenges. Available at: https:// www.dur.ac.uk/ beacon/ socialjustice/ researchprojects/ cbpr/ (accessed 11 March 2014).

Dziak J.J., Nahum-Shani I., Collins L.M., 2012. Multilevel factorial experiments for developing behavioral interventions: Power, sample size, and resource considerations. Psychological Methods 17(2): 153-175.

Eck J.E., Liu L., 2008. Contrasting simulated and empirical experiments in crime prevention. Journal of Experimental Criminology 4: 195-213.

Elgethun K., Fenske R.A., Yost M.G., Palcisko G.J., 2003. Time-location analysis for exposure assessment studies of children using a novel global positioning system instrument. Environmental Health Perspectives 111(1): 115122.

Elwood S.A., Martin D.G., 2000. "Placing” interviews: Location and scales of power in qualitative research. The Professional Geographer 52(4): 649-657.
Evans J., Jones P., 2011. The walking interview: Methodology, mobility and place. Applied Geography 31(2): 849-858.

Fisher P.A., Ball T.J., 2003. Tribal participatory research: Mechanisms of a collaborative model. American Journal of Community Psychology 32(3/4): 207-216.

Garling T., Golledge R.G. (eds), 1993. Behavior and environment: Psychological and geographical approaches. Elsevier Science Publishers, Amsterdam.

Gibson C., Brennan-Horley C., Warren A., 2010. Geographic information technologies for cultural research: Cultural mapping and the prospects of colliding epistemologies. Cultural Trends 19(3): 325-348.

Golledge R.G., Klatzky R.L., Loomis J.M., Speigle J., Tietz J., 1998. A geographical information system for a GPSbased personal guidance system. International Journal of Geographical Information Science 12(7): 727-749.

Golledge R.G., Stimson R.J., 1997. Spatial behaviour. A geographic perspective. Guilford Press, New York, London.

González M.C., Hidalgo C.A., Barabási A.L., 2008. Understanding individual human mobility patterns. Nature 453(5): 779-782.

Goss J., Leinbach T., 1996. Focus groups as alternative research practice: Experience with transmigrants in Indonesia. Area 28(2): 115-123.

Greenberg Raanan M., Shoval N., 2014. Mental maps compared to actual spatial behavior using GPS data: A new method for investigating segregation in cities. Cities 36: 28-40. doi:10.1016/j.cities.2013.09.003.

Hägerstrand T., 1970. What about people in regional science? Papers of Regional Science Association 24: 7-21.

Hussein A., 2009. The use of triangulation in social sciences research: Can qualitative and quantitative methods be combined? Journal of Comparative Social Work 1: 1-12. Available at: http:// www.jcsw.no/ ?page=issueContent\&issue=issue04 (accessed 11 March 2014).

Ingold T., Lee J., 2008. Ways of walking: Ethnography and practice on foot. Ashgate, London.

Janarthanam S., Lemon O., Liu X., Bartie P., Mackaness W., Dalmas T., Goetze J., 2012. Integrating location, visibility, and question-answering in a spoken dialogue system for pedestrian city exploration. Paper presented at SemDial 2012 16th Workshop on the semantics and pragmatics of dialogue. Paris, France.

Janarthanam S., Lemon O., Bartie P., Dalmas T., Dickinson A., Liu X., Mackaness W., Webber B., 2013. Evaluating a city exploration dialogue system with integrated question-answering and pedestrian navigation. Paper presented at the Association for Computer Linguistics ACL 2013, Sofia, Bulgaria.

Janelle D.G., Goodchild M.F., Klinkenberg B., 1988. Spacetime diaries and travel characteristics for different levels of respondent aggregation. Environment and Planning A 20(7): 891-906.

Jick T.D., 1979. Mixing qualitative and quantitative methods: Triangulation in action. Administrative Science Quarterly 24: 602-611.

Kidner D., Higgs G., White S. (eds), 2003. Socio-economic applications of geographic information science (innovations in GIS). Taylor and Francis, London.

Kindon S., Pain R., Kesby M. (eds), 2007. Participatory action research approaches and methods: Connecting people, participation and place. Routledge, London.

Kirk R., 1995. Experimental design: Procedures for the behavioral sciences (3rd ed.). Brooks/Cole, Pacific Grove, CA. 
Kitzinger J., 1995. Introducing focus groups. British Medical Journal 311: 299-302.

Krueger R.A., Casey M.A., 2008 Focus groups: A practical guide for applied research. Sage, London.

Kwan M.P., 2012. The uncertain geographic context problem. Annals of the Association of American Geographers 102(5): 958-968.

Kwan M.P., Knigge L., 2006. Doing qualitative research using GIS: An oxymoronic endeavor? Environment and Planning A 38(11): 1999-2002.

Lee H.J., Joh C.H., 2010. Tourism behaviour in Seoul: An analysis of tourism activity sequence using multidimensional sequence alignments. Tourism Geographies 12(4): 487-504

Li Ch., 2006. User preferences, information transactions and location-based services: A study of urban pedestrian wayfinding. Computers, Environment and Urban Systems 30(6): 726-740.

Liu L., Hou A., Biderman A., Ratti C., 2009. Understanding individual and collective mobility patterns from smart card records: A case study in Shenzhen. $12^{\text {th }}$ International IEEE Conference on Intelligent Transportation Systems, Institute of Electrical and Electronics Engineers. Available at: http:/ / dx.doi.org/ 10.1109/ ITSC.2009.5309662 (accessed 13 March 2014).

Longhurst R., 2003. Semi-structured interviews and focus groups. In: Clifford N.J., Valentine G. (eds), Key methods in geography. Sage, London: 117-132.

Lowery D.R., Morse W.C., 2013. A qualitative method for collecting spatial data on important places for recreation, livelihoods, and ecological meanings: Integrating focus groups with public participation geographic information systems. Society \& Natural Resources 26(12): 1422-1437.

Mackaness W., Bartie P., Sanchez-Rodilla Espeso C., 2014. The 'when, how and what' of text based wayfinding instructions for urban pedestrians. Paper presented at GISRUK 2014 Conference, University of Glasgow, Glasgow, Scotland.

McKenzie M., Debbage K., 1990. Spatial pattern of visitor behaviour: A case study of the North Carolina Zoological Park. Geographical Bulletin 32(2): 100-109.

McKercher B., Lau G., 2008. Movement patterns of tourists within a destination. Tourism Geographies 10(3): 355-374.

Mendoza C., More'n-Alegret R., 2012. Exploring methods and techniques for the analysis of senses of place and migration. Progress in Human Geography 37(6): 762-785.

Mertens D.M., Ginsberg P.E. (eds), 2008. The handbook of social research ethics. Sage, London.

Millonig A., Gartner G., 2007. Monitoring pedestrian spatio-temporal behaviour. In: Gottfried B (ed.), Workshop on behaviour monitoring and interpretation BMI 07: 29-42. Available at www.tzi.de (accessed 11 March 2014).

Miskelly F., 2005. Electronic tracking of patients with dementia and wandering using mobile phone technology. Age and Ageing 34(5): 497-499.

Moles M., 2008. A walk in thirdspace: Place, methods and walking. Sociological Research Online 13(4). Available at: http:// www.socresonline.org.uk/ 13/4/2.html (accessed 13 March 2014).

Murakami E., Wagner D.P., 1999. Can using global positioning system (GPS) improve trip reporting? Transportation Research Part C: Emerging Technologies 7(2): 149-165.

Nisbett R.E., Wilson T.D., 1977. Telling more than we can know: Verbal reports on mental processes. Psychological Review 84(3): 231-259.
Orellana D., Bregt A.K., Ligtenberg A., Wachowicz M., 2012. Exploring visitor movement patterns in natural recreational areas. Tourism Management 33(3): 672-682.

Orellana D., Wachowicz M., 2011. Exploring patterns of movement suspension in pedestrian mobility. Geographical Analysis 43(3): 241-60.

Pain R., 2008. Ethical possibilities: Towards participatory ethics. Children's Geographies 6(1): 104-108.

Pain R., Francis P., 2003. Reflections on participatory research. Area 35(1): 46-54.

Pain R., Kindon S., 2007. Participatory geographies. Environment and Planning A, 39(12): 2807-2812.

Pavlovskaya M., 2006. Theorizing with GIS: A tool for critical geographies? Environment and Planning A 38(11): 2003-2020.

Pettersson R., Zillinger M., 2011. Time and space in event behaviour: Tracking visitors by GPS. Tourism Geographies 13(1): $1-20$

Philip L.J., 1998. Combining quantitative and qualitative approaches to social research in human geography - an impossible mixture? Environment and Planning A 30(2): 261-276.

Phillips M.L., Hall T.A., Esmen N.A., Lynch R., Johnson D.L., 2001. Use of global positioning system technology to track subject's location during environmental exposure sampling. Journal of Exposure Analysis E Environmental Epidemiology 11(3): 207-215.

Pratt G., 2002. Studying immigrants in focus groups. In: Moss P (ed.), Feminist geography in practice. Blackwell, Oxford: 214-229.

Prince M., Brown S., Heathcote A., 2012. The design and analysis of state-trace experiments. Psychological Methods 17(1): 78-99.

Quiroga C.A., Bullock D., 1998. Travel time studies with global positioning and geographic information systems: An integrated methodology. Transportation Research Part C: Emerging Technologies 6(1): 101-127.

Rainham D., Krewski D., McDowell I., Sawada M., Liekens B., 2008. Development of a wearable global positioning system for place and health research. International Journal of Health Geographics 7(1): 59.

Ratti C., Pulselli R.M., Williams S., Frenchman D., 2006. Mobile landscapes: Using location data from cell-phones for urban analysis. Environment E Planning B 33(5): 727-748.

Research Ethics Code of Practice: Summary version 2005, 2008. Children's Geographies 6(1): 95-108.

Richardson D.B., Volkow N.D., Kwan M., Kaplan R.M., Goodchild M.F., Croyle R.T., 2013. Spatial turn in health research. Science 339 (6126): 1390-1392.

Ricketts Hein J., Evans J., Jones P., 2008. Mobile methodologies: Theory, technology and practice. Geography Compass 2: $1266-1285$

Rocheleau D., 1995. Maps, numbers, text and context: Mixing methods in feminist political ecology. The Professional Geographer 47(4): 458-466.

Santé I., García A.M., Miranda D., Crecente R., 2010. Cellular automata models for the simulation of real-world urban processes: A review and analysis. Landscape and Urban Planning 96: 108-122.

Sheller M., Urry J., 2006. The new mobilities paradigm. Environment and Planning A 38(2): 207-226.

Shoval N., 2008. Tracking technologies and urban analysis. Cities 25(1): 21-28.

Shoval N., 2010. Monitoring and managing visitors flows in destinations using aggregate GPS data. In Gretzel R.L., 
Fuchs M. (eds), Information and communication technologies in tourism. Springer, Vienna, New York: 171-184.

Shoval N., Isaacson M., 2006. Application of tracking technologies to the study of pedestrian spatial behavior. The Professional Geographer 58(2): 172-183.

Shoval N., Isaacson M., 2007. Tracking tourists in the digital age. Annals of Tourism Research 34(1): 141-159.

Shoval N., Isaacson M., 2010. Tourist mobility and advanced tracking technologies. Routledge, London.

Shoval N., Kwan M., Reinau K.H., Harder H., 2014. The shoemaker's son always goes barefoot: Implementations of GPS and other tracking technologies for geographic research. Geoforum 51: 1-5.

Song C., Qu Z., Blumm N., Barabási A.L. 2010. Limits of predictability in human mobility. Science 327: 1018-1021.

Stopher P.R., Wilmot C.G., 2000. Some new approaches to designing household travel surveys-time-use diaries and GPS. Transportation Research Board Annual Meeting, Paper\# 00. T. 1163.

Szalai A., 1972. The use of time: Daily activities of urban and suburban populations in twelve countries. Mouton, Hague, Paris.

Talen E., 2000. Bottom-up GIS: A new tool for individual and group expression in participatory planning. Journal of American Planning Association 66: 279-294.

Thornton P.R., Williams A.M., Shaw G., 1997. Revisiting time-space diaries: An exploratory case study of tourist behaviour in Cornwall, England. Environment and Planning A 29(3): 1847-1867.

Thrift N., 2005. Thorsten Hägerstrand and social theory. Progress in Human Geography 29(3): 337-340.
Thyer B.A., 2012. Quasi-experimental research designs. Oxford University Press, Oxford, New York.

Wilkinson S., 1998. Focus groups in feminist research: Power, interaction, and the construction of meaning. Women Studies International Forum 24: 111-125.

Wolf J., Guensler R., Bachman W., 2001. Elimination of the travel diary: Experiment to derive trip purpose from global positioning system travel data. Journal of the Transportation Research Board 1768(1): 125-134.

Wolf J., Loechl M., Thompson M., Arce C., 2003. Trip rate analysis in GPS-enhanced personal travel surveys. Transport Survey Quality and Innovation 28: 483-98.

Wylie J., 2005. A single day's walking: Narrating self and landscape on the South West Coast Path. Transactions of the Institute of British Geographers 30: 234-247.

Xia J., Arrowsmith C., Jackson M., Cartwright W., 2008. The wayfinding process relationships between decision-making and landmark utility. Tourism Management 29(3): 445-57.

Xia J., Zeephongsekul P., Packer D., 2011. Spatial and temporal modelling of tourist movements using semi-Markov processes. Tourism Management 32(4): 844-851.

Zenk S.N., Schulz A.J., Matthews S.A., Odoms-Young A., Wilbur J., Wegrzyn L., Gibbs K., Braunschweig C., Stokes C., 2011. Activity space environment and dietary and physical activity behaviors: A pilot study. Health $\mathcal{E}$ Place 17(5): 1150-1161.

Zito R., d’Este G., Taylor M.A.P., 1995. Global positioning systems in the time domain: How useful a tool for intelligent vehicle-highway systems? Transportation Research Part C: Emerging Technologies 3(4): 193-209. 